\title{
EL BAÚL DE LA TÍA JESUSA ${ }^{1}$
}

\author{
Ana María Romero Yebra ${ }^{2}$
}

En un lugar de La Mancha de cuyo nombre no quiero olvidarme, estaba la casa de mis abuelos. Allí pasé muchos veranos de mi infancia, no por aliviarme de los rigores del calor madrileño, pues el clima era bastante parecido, sino por disfrutar de todas aquellas cosas que para los niños de ciudad eran inalcanzables y en el pueblo podíamos disfrutar plenamente: subir a los árboles, bañarnos en el río, montar en burro, jugar en la calle, observar de cerca insectos, pájaros y plantas, meterse en medio de un rebaño y agarrar los ásperos vellones polvorientos de la lana de las ovejas y ver las labores de los campesinos que se afanaban con la siega, la trilla en las eras y ya, al final del verano, con la vendimia.

La casa de aquellos meses era un caserón de dos plantas con una cocinilla de verano, que daba al patio y otra mayor y más resguardada entre las habitaciones de la planta baja. Bajo la escalera estaba la despensa donde siempre había huevos, jamón y orzas con chorizos y torreznos. Junto a la cocina, un comedor y cinco dormitorios completaban el interior de la casa.

Desde el porche se salía a un corral donde convivían pacíficamente conejos, pollos y gallinas y a un hermosos patio sombreado por tres olivos y una parra que se perfumaba

\footnotetext{
${ }^{1}$ Fecha de recepción: 27/11/2014.

Fecha de aceptación: 29/11/2014.

${ }^{2}$ La escritora madrileña Ana María Romero Yebra inicia su prolífica y exitosa carrera literaria en la década de los ochenta. Entre sus más de setenta obras, se encuentran importantes poemarios para adultos como Entero para mí, Isla de Brétema, Cantos de arcilla, Horario de la hondura, Mirando escaparates, El llanto de Penélope o Luminaria (la última de sus obras, homenaje a su madre) y libros infantiles que contienen poemas, nanas y canciones entre los que destacan Hormiguita negra, La vaca Dosinda, Verdes amigos, El memoriápodo, Doña Pescadilla, Ronda de Nanas, La princesa aburrida, Columpio de versos, Versos en la mochila, etc. Asimismo se ha adentrado en el género narrativo a través del relato corto para mayores y el cuento troquelado para los pequeños; $\square$ cibeles71@hotmail.com.
} 
al anochecer con el aroma de la hierbabuena y las celindas que crecían en uno de los andeles. La presencia de un gato - primero Cañón, luego Saturnino y más tarde Lindome permitía ese contacto directo con una mascota a la que amar y con la que compartir juegos que Madrid me negaba.

Mis abuelos habían muerto ya y la casa la habitaban dos tías solteras; la tía Paquita y la tía Jesusa. Jesusa se ocupaba de todo lo concerniente a las labores de la casa y la comida y la tía Paca, que había aprendido Corte y Confección en Madrid, desempeñaba a lo largo del día y desde muy temprano, su trabajo de modista. Había varias aprendizas que venían por las tardes a ayudarla a coser y la casa era siempre un jubileo de mujeres que entraban y salían para traerle telas, probarse la ropa o recogerla una vez terminada.

Pero yo de eso no estaba pendiente pues pasaba casi todas las horas con otros chicos y chicas del barrio en el río, en las ruinas del molino, subiendo y bajando cerros dorados por el sol y las mieses o en las eras, pidiendo que me dejaran subir en el trillo o darle la vuelta a la parva con aquellas grandes horcas de madera. El dulce control de las tías me daba libertad para hacer todo aquello y aparecer poco antes de las horas de las comidas.

De aquella casa me gustaba todo: las grandes camas de madera, las mesitas de noche con cajones llenos de recuerdos, las cómodas que guardaban toallas y ropa blanca, los lavabos de cada dormitorio, con su espejo, y la jarra y la jofaina de loza blanca, las repisas llenas de fotos familiares, los antiguos armarios de luna... pero lo más fascinante para mí era el baúl de a tía Jesusa que estaba en una de las habitaciones del piso de arriba.

Era el baúl enorme, de madera oscura con cantoneras y herrajes de metal. Cada vez que su tapa se levantaba, se abría ante mí un mundo mágico que exaltaba mi fantasía y me hacía soñar con otros tiempos diferentes y otras costumbres que yo no había conocido. Allí, entre papeles de seda y olor a espliego, estaba guardado el ajuar de la tía: una gran colección de sábanas con hermosos bordados de letras y flores, caladas por el filtiré y los deshilados, bellas mantelerías adamascadas, toallas de hilo con las iniciales de la tía Jesusa entre vainicas y flecos, camisones de raso ornados de encajes, pasacintas y lazadas, peinadores de seda, pañitos, cubrebandejas, puntillas de crochet... todo cuando uno pudiera imaginarse estaba allí, en el fabuloso baúl de la tía Jesusa. 
Mi tía no se casó nunca porque su novio murió "de la guerra". No fue uno de los innumerables jóvenes que cayó en el campo de batalla ni lo mataron en los fusilamientos y ejecuciones que se hicieron durante la guerra por ambas partes. En aquellos años que siguieron, de penuria, escasez y enfermedades, contrajo la tuberculosis y a causa de ella murió. La tía Jesusa se quedó con su cuerpo y su ajuar intactos y también con el recuerdo imborrable de aquel único amor que había tenido. Jamás quiso casarse con otro y el contenido de aquel baúl, pensado para encuentros amorosos y comidas familiares, se fue estrenando para la cama y la mesa que compartió con su hermana únicamente.

En aquellos veranos me sorprendía encontrarme envuelta, cuando me acostaba, entre sabanas tan hermosas y disfrutar de aquel derroche de tiras bordadas, encajes y ramos hechos con hilos de suavísimos colores sobre el blanco deslumbrante.

- Te he puesto en la cama mi juego de novia -me decía-. Ya que no pude estrenarlo con Andrés, ahora lo estrenas tú.

Otras veces era un precioso mantel el que salía de su baúl con ocasión de las fiestas patronales o de alguna comida familiar en la que nos reuníamos todos.

Además del baúl, me gustaba el canario muerte y lo miraba muchas veces. En el patio estaba emparedado un canario que su novio le regaló. Cuando se murió de viejo, la tía Jesusa no quiso enterrarlo ni echárselo al gato. Le ató en el frágil cuello un lacito de raso azul, arrancó una de las piedras de la pared, blanqueo el hueco con cal y acomodó allí al pájaro poniéndole un cristal por delante que permitía seguir viéndole, como si estuviera en un fanal a una hornacina.

Año tras año, el diminuto cadáver seguía allí, presente e incorrupto como cuerpo de santo y aunque su color amarillo iba empalideciendo, daba a sensación de que estaba dormido.

Yo le pregunté muchas veces, mientras lo contemplaba, como había tenido semejante ida. 
La verdad es que no sé por qué se me ocurrió - decía invariablemente-. Yo quería mucho al canario y me daba lástima dejar de verlo. Mira, -añadía con su buen humor y su extraordinario gracejo- si hubiera hecho lo mismo con mi novio, ahora los tendría ahí a los dos, en la pared metidos detrás de un cristal, claro que él estaría mucho más feo... ¡Y qué poco lo disfruté, madre mía! ¡Tanto respecto, tanta moralidad! ¡Me cagüen la mar que se fue al otro barrio sin darme siguiera un beso en condiciones! Pero claro, ¿cómo iba a dármelo si nos veíamos a través de la reja, pero él en la calle y yo allí en lo alto, que no le veía más que la cresta y no alcanzábamos a rozarnos la mano siquiera. Cuando me lo encontraba en misa y me daba agua bendita al entrar, era cuando nuestros dedos se tocaban y iqué chispazo! Me recorría una cosa por todo el cuerpo... y me temblaban las piernas. Pero no pasaba nada; él se iba para la parte de los hombres y yo rezaba delante, donde nos poníamos las mujeres y a la salida, aunque fuéramos hacia el paseo ni se me arrimaba. Decían que eras una fresca, una golfa, sí dejabas al novio que te tocara. ¡Ay cuantas tonterías he tenido que aguantar! Por eso, ahora, cuando veo pasar por la calle a las parejas, pegados como si fueran uno, comiéndose con los ojos y dándose esos besos de tornillo que cortan la respiración, disfruto mirando cómo se achuchan y digo: ¡Qué leche! ¡Hacen muy bien! No como yo, que se me fue y me quedé sin catarlo...

- Pero tía, tu podías haberte casado después. Dice mamá que siempre te han salido muchos pretendientes...

- Pues sí, hermosa, más que a la Paca. Y eso que era mucho más guapa y más joven que yo. Pero no quise. Ya me había acomodado a esta vida a que estuviéramos juntas y hubiera sido un lío que entraran unos pantalones en esta casa, o dejarla sola si me iba yo con él. Y ella debió de pensar lo mismo, porque ahí la tienes, soltera también. Tuvo sus novios pero no se decidió a casarse con ninguno.

- Yo no encontré tampoco otro que me gustara, siempre me daba por compararlos con Andrés y todos salían perdiendo. Ahora que ya soy vieja, nada, pero antes sí tuve muchas y buenas oportunidades...

- ¿Cómo que ya eres vieja? Sí ahora te siguen saliendo novios... podías haberte casado con Román, el de la panadería... 
- ¿Y tú cómo sabes eso, niña?

- Oí una noche a papá y mamá comentándolo en el comedor este invierno. Papá decía que Román llevaba toda la vida detrás de ti y que a él le gustaba ese hombre, que era muy bueno y muy formal y que sí os casabais seguramente iba a salir bien.

- ¡Bah, bah, bah! ¡Qué sabrá tu padre! ¡Los hombres son muy tontos! Fíjate que este Román, como le día calabazas de joven un montón de veces, al final se casó con otra. Y al quedarse viudo hace dos años, volvió a la carga: -Jesusa que te quiero, que con la panadería viviremos muy bien, que vas a estar como una reina... y yo que no, que no y que no. El muy bobo, unos meses después se buscó a otra y ya en vísperas de la boda vuelve otra vez con la oferta: - Que sí me dices que sí, dejo a la María y nos casamos cuando tú mandes, que esto es un apaño porque necesito a una mujer, pero a la que quiero es a ti... piénsatelo, Jesusa, que te sigo queriendo como siempre...

- Y tú ni te lo pensaste, claro.

- Pero niña, ¿tú te crees que después de un montón de años diciéndole que no, voy a decirle que sí cuando ya está a punto de casarse con otra? ¡Pues vaya faena que iba a hacerle a la María! ¡Que se casara con ella y me dejara tranquila! Además, no lo quise de joven, menos lo iba a querer de viejo... ¡Sí hasta cambié de panadería y me fui a comprar a la de Tito por no darle la oportunidad de verme siquiera! Y la Paca me decía: - No sé por qué no traes el pan de Román; está mucho más bueno que este... y yo callada, aunque la Paca se olía algo...

$$
- \text { II }-
$$

Vinieron todos: Pedro, Águeda y los otros primos, la familia de Valencia, los amigos de siempre, la vecindad y muchas personas que vivían en otros barrios del pueblo...

La casa volvió a llenarse de gente, como en los mejores tiempos y se perfumó con el aroma del cocido que prepararon Nati y Josefa para que pudieran comer algo, antes de volver, los que habían llegado de fuera. 
Compartí con mis hermanas el dolor de acompañarla en el hospital los últimos días, cuando ya no era ella. Sabíamos que estaba viva porque su pecho subía y bajaba muy despacio, acompasadamente y emitía cada vez un quejido ahogado, como el piar de un pájaro recién nacido. Pero sus ojos estaban siempre cerrados, no hablaba y no respondía a los estímulos de nuestra voz ni de nuestras caricias. No podía creer que aquel caudal de ternura y de vitalidad se agotara y hasta que entraron las enfermeras y la desconectaron de tubos y claves, pensé que en cualquier momento iba a sentarse en la cama y regañarme cariñosamente diciendo:

- ¡Pero bueno! ¿Se puede saber qué haces aquí conmigo, en vez de estar atendiendo a tu marido y a tus chicas?

Aquel milagro no se produjo. Ella no podría hablar nunca ni volver a levantarse más. Tampoco vio la mañana gris del 30 de diciembre en que la enterramos, ni la arcilla roja que todos trajimos pegada a los zapatos desde el cementerio por la lluvia caída durante toda la noche, ni las coronas y ramos de los que la queríamos, con las cintas batiéndose en el aire, rompiendo el silencio con el crujir suave del celofán e hiriendo la tristeza del día con la luz de los claveles, las gerberas y la espada en flor de los gladiolos.

La vuelta a aquella casa, donde ya nunca estaría ella, me pareció algo extraño, carente de sentido. Una vez acabado el desfile de personas que querían seguir acompañándonos y ya de viaje de vuelta los primos, subí a una de las habitaciones de arriba. Allí estaba, como siempre, mágico y sugerente, el baúl de la tía Jesusa.

Me pareció una profanación levantar su tapa sin estar ella presente, pero necesitaba retornar a aquella época de infancia, a aquellos veranos inolvidables, a sentirla como entonces a través de sus cosas...

La magia del baúl se fue con ella. También había desaparecido aquel olor a nuevo y a hierbas aromáticas que tenía cuanto encerraba. Los manteles, todos estrenados, me eran conocidos porque sobre ellos había comido muchas veces y las sábanas y almohadones, desgastados por años y años de lejía y detergentes, conservaban su blancura 
pero tenían ajados los encajes, las iniciales y los pasacintas. Las toallas bordadas habían desaparecido y tampoco quedaban camisones, agotados, sin duda, por el uso diario.

No sé qué me hizo pensar que todo iba a estar igual que cuando yo era pequeña, pero no, la muerte también había llegado a aquel baúl volviendo su contenido mágico en un montón de trapos viejos y casi inservibles.

Ni siquiera pude conservarlo como recuerdo. Unos años después de morir la tía Jesusa, la tía Paca, respaldada por las intrigas de una de mis primas y su marido, vendió la casa con todo lo que había en ella y se marchó a terminar sus días en una residencia de ancianos que había en aquel lugar de la Mancha.

Por supuesto la prima intrigante administró el dinero y antes de dar la llave a los compradores se llevó de la casa cuanto le apeteció, no sé si para ella o para algún anticuario o chamarilero. Pero cuando la pala de excavadora redujo la casa a escombros para hacer una edificación nueva, seguro que aún estaba el canario en la pared y en uno de los dormitorios de arriba, el baúl de la tía Jesusa. 